\title{
Colonoscopy-assisted application of a 14/6t over-the-scope clip for treatment of a bleeding Dieulafoy lesion in the distal jejunum
}

A 69-year-old patient with massive hematemesis was transferred to our intensive care unit. Additional clinical symptoms were melena, fatigue, and severe anemia with an initial hemoglobin level of $6.9 \mathrm{~g} / \mathrm{dL}$. The patient's medical history was uneventful and without significant comorbidity. Previous endoscopic examinations performed elsewhere had revealed an angiodysplastic lesion in the gastric fundus, as well as two non-bleeding angiodysplastic lesions in the cecum, which had been treated with argon plasma coagulation (APC) and hemoclip application. Unfortunately, the patient's physical condition progressively worsened, with severe gastrointestinal (GI) bleeding, tachycardia, and hypotension despite endoscopic intervention and the transfusion of numerous units of red blood cells $(n=12)$ and fresh frozen plasma (FFP) over the next 72 hours. The clinical course was additionally complicated by aspiration-induced pneumonia and antibiotic treatment was required (ceftriaxone $2 \mathrm{~g}$ once daily and metronidazole $500 \mathrm{mg}$ three times per day).

Because further episodes of significant hematemesis occurred repeatedly and gastroscopy failed to identify the bleeding source, we decided to intensify the diagnostic approach and performed an upper Gl single-balloon enteroscopy (SIF-Q180; Olympus), which identified a Dieulafoy-like pulsating lesion in the distal jejunum ( $>$ Fig.1). The lesion was marked with two hemoclips and definitive hemostasis was achieved following application of an over-the-scope clip (OTSC; Ovesco, Tübingen, Germany). For this purpose, the $14 / 6$ t OTSC clip was mounted on a colonoscope (CF-H165L; Olympus) and successfully released at the marked site of bleeding in the distal jejunum ( Video 1 ).

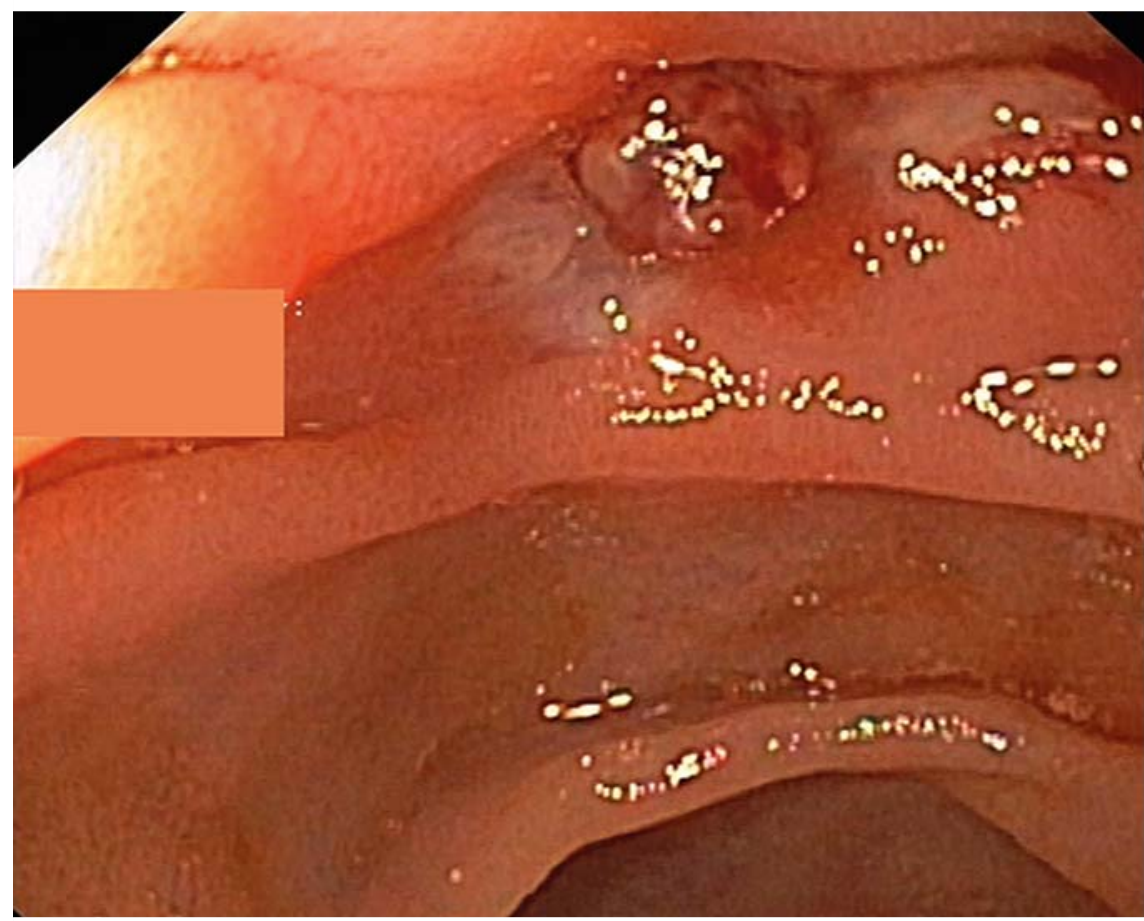

- Fig. 1 Image during single-balloon enteroscopy showing a pulsating Dieulafoy lesion in the distal jejunum.

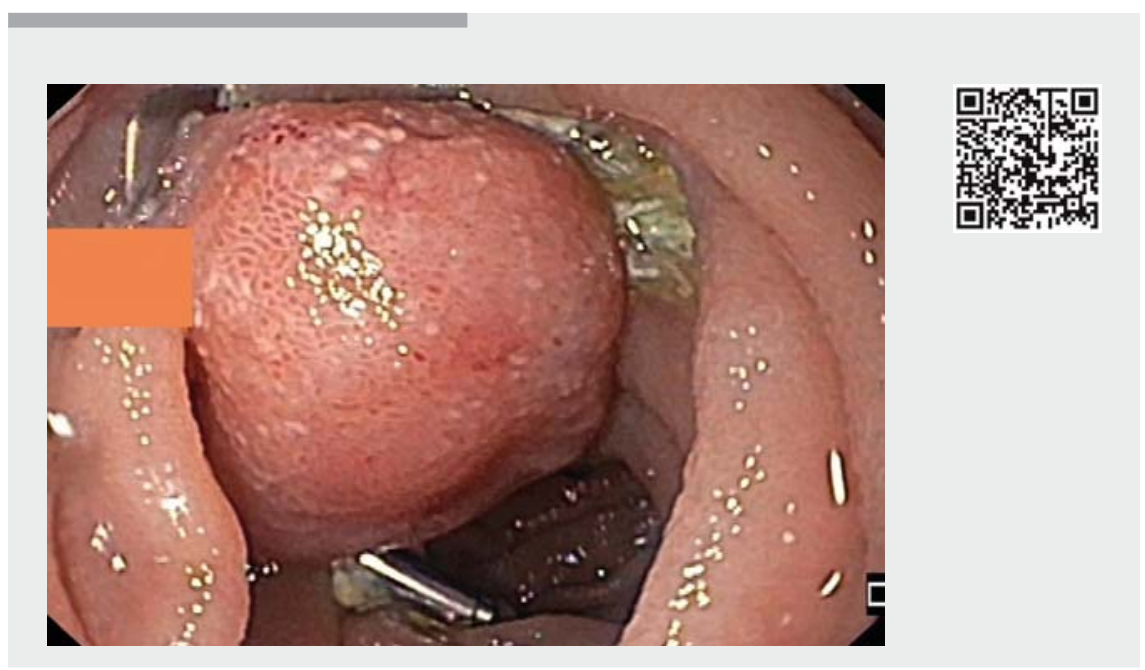

Video 1 Colonoscopy-assisted placement of a 14/6t over-the-scope clip to treat a bleeding Dieulafoy lesion in the distal jejunum, with follow-up after 6 days showing ongoing hemostasis. 


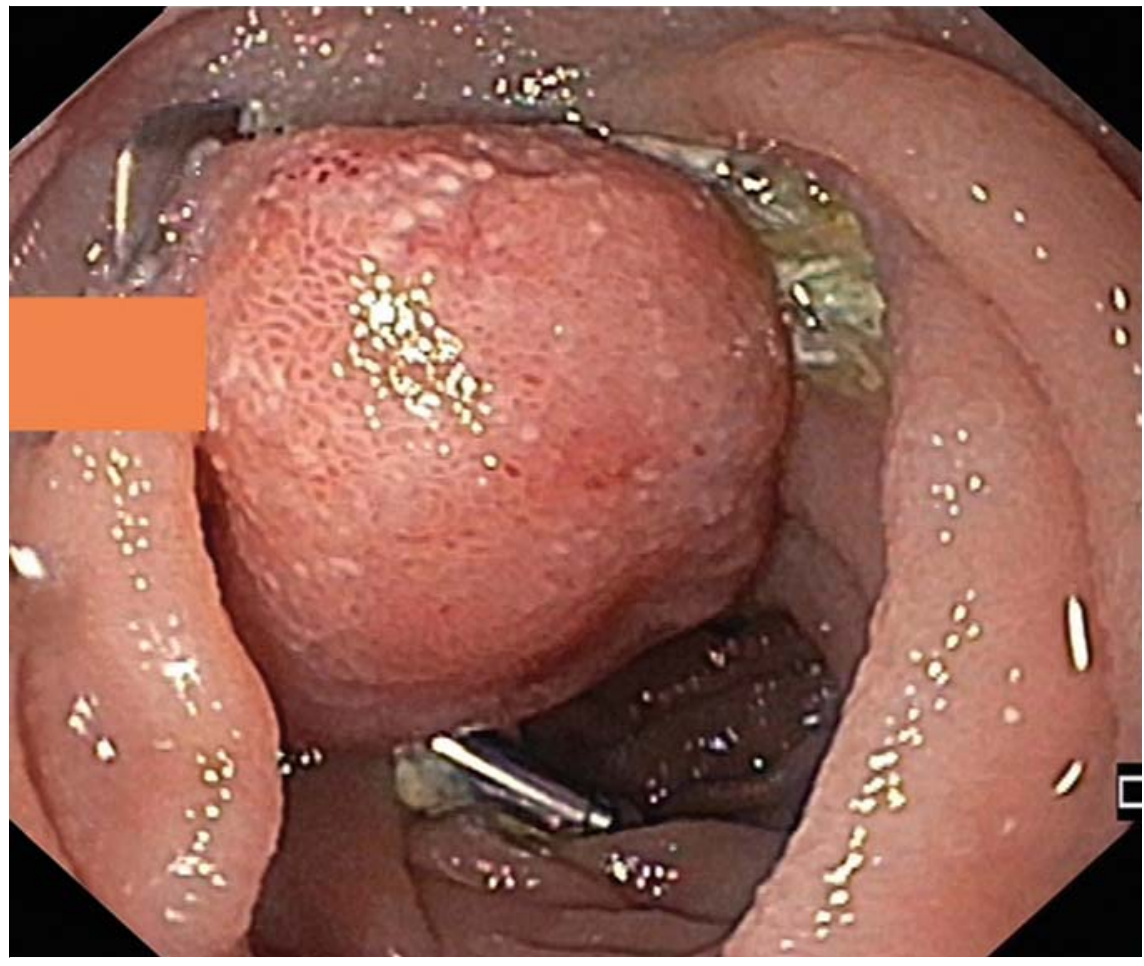

- Fig. 2 Endoscopic image showing ongoing hemostasis at follow-up examination on day 6 after application of the over-the-scope clip for a jejunal Dieulafoy lesion.

\section{References}

[1] Gralnek IM, Dumonceau JM, Kuipers E] et al. Diagnosis and management of nonvariceal upper gastrointestinal hemorrhage: European Society of Gastrointestinal Endoscopy (ESGE) Guideline. Endoscopy 2015; 47: a1 a46

[2] Yano T, Yamamoto H, Sunada K et al. Endoscopic classification of vascular lesions of the small intestine (with videos). Gastrointest Endosc 2008; 67: 169-172

[3] Kasapidis P, Georgopoulos P, Delis V et al. Endoscopic management and long-term follow-up of Dieulafoy's lesions in the upper GI tract. Gastrointest Endosc 2002; 55: $527-531$

[4] Wedi E, von Renteln D, Gonzalez S et al. Use of the over-the-scope-clip (OTSC) in nonvariceal upper gastrointestinal bleeding in patients with severe cardiovascular comorbidities: a retrospective study. Endosc Int Open 2017; 5: E875-E882

\section{Bibliography}

DOI https://doi.org/10.1055/a-0833-8079

Published online: 8.2.2019

Endoscopy 2019; 51: E92-E93

(c) Georg Thieme Verlag KG

Stuttgart · New York

ISSN 0013-726X

The further clinical course was uneventful and the patient rapidly recovered without restrictions. Endoscopic follow-up examination on day 6 after the procedure showed ongoing hemostasis ( $\bullet$ Fig. 2).

In conclusion, severe small-intestinal bleeding is a rare event that is often associated with a complex clinical course and a high mortality [1]. The presented case with an arterial bleeding Dieulafoy lesion, type 2b (Yamamoto classification) is typically found in patients with cardiovascular risk factors [2,3]. It was previously shown that first- and secondline treatment with the OTSC in non-variceal upper $\mathrm{Gl}$ bleeding is a highly effective alternative strategy to surgery and other endoscopic techniques [4]. To the best of our knowledge, this case provides the first evidence that application of a $14 / 6 t$ OTSC is technically safe and effective in the treatment of Dieulafoy lesions in the distal jejunum of selected patients.

Endoscopy_UCTN_Code_TTT_1AQ_2AZ

\section{Competing interests}

None

The authors

Carlo Jung, Steffen Kunsch, Sebastian Bremer, Richard F. Knoop, Volker Ellenrieder, Edris Wedi

Department of Gastroenterology and Gastrointestinal Oncology, Center of Interdisciplinary Endoscopy, University Medical Center Göttingen, Germany

\section{Corresponding author}

\section{Edris Wedi, MD}

Department of Gastroenterology and Gastrointestinal Oncology, Center of Interdisciplinary Endoscopy, University Medical Center Göttingen, Georg-AugustUniversity, D-37075 Göttingen, Germany edris.wedi@med.uni-goettingen.de

\section{ENDOSCOPY E-VIDEOS}

https://eref.thieme.de/e-videos

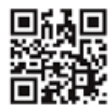

Endoscopy E-Videos is a free access online section, reporting on interesting cases and new techniques in gastroenterological endoscopy. All papers include a high quality video and all contributions are freely accessible online.

This section has its own submission website at

https://mc.manuscriptcentral.com/e-videos 